\title{
Injury prevention programmes in primary care: a high risk group or a whole population approach?
}

\author{
Denise Kendrick, Patricia Marsh
}

Abstract

Objective-To examine the relationship between risk factors for childhood unintentional injury and injury outcome and to assess the feasibility of using risk factors to identify children at high risk of injury.

Setting-One general practice in Nottingham, UK.

Method-A postal questionnaire survey to all parents of children registered with the practice $(n=771)$ to obtain data on risk and sociodemographic factors. All children still registered with the practice one year later were followed up for occurrence of a medically attended injury.

Results-The response rate was $78 \%$. The injury rate over the follow up year was 246 injuries per 1000 children. Previous medically attended injury was associated with each of the injury outcomes (odds ratio (confidence interval) for all attendances, 2.33 (1.37 to 4.05); for accident and emergency attendances, 2.27 (1.15 to 4.4); and for primary health care team attendances, 2.58 (1.33 to 5.0)). Male sex was associated only with accident and emergency department attendance (odds ratio 2.13 (1.06 to 4.2$)$ ). Maternal age and previous injury were associated with a higher number of injuries in the subsequent year on univariate and multivariate analyses. The sensitivity and positive predictive value of the risk factors were low, except for previous injury and male sex. The number of children needing an injury prevention intervention to prevent one injury as identified by the risk factors was not significantly different from that required if a whole population approach were to be used.

Conclusion-Primary care based injury prevention programmes, at present, should not be targeted at children identified as being at 'high risk' of injury. Nevertheless, a larger study using a wider cross section of the population is needed to address this issue further.

(Injury Prevention 1997; 3: 170-175)

Keywords: primary care; injury prevention programme; preventive strategy.

This paper presents the results of a study undertaken at one general practice in the UK as part of the process of planning an injury prevention intervention study. As part o $\vec{\oplus}$ planning the study, it was important to con $\overrightarrow{\vec{\omega}}$ sider whether the interventions should bo offered to all children or only to childre identified as being at high risk.

Many factors have been identified as being associated with an increased risk of unintenฮ tional injury in childhood, such as male sex $\frac{\text { O }}{2}$ family size and structure, previous medically attended injury, young maternal age at birth of first child, and various measures of socio $\frac{\mathrm{T}}{\mathbb{Q}}$ economic status. ${ }^{1-10}$ Over recent years there $\frac{\mathbb{E}}{\mathcal{E}}$ have been suggestions, including the govern ments health strategy for the UK, ${ }^{341112}$ that injury prevention programmes should be tare geted at children at high risk of injury.

Several workers have discussed the difficulo ties of doing this. The Child Health an Education Study found that case definition was important in determining which factore were associated with injury. So, for example $\frac{0}{2}$ the risk factors associated with having one o를 more medically attended injuries differed from those associated with admission to hospital fo an injury. ${ }^{10} \mathrm{~A}$ second problem is that the sensitivity and positive predictive value of some factors in predicting which children will have injuries has been found to be low. This suggests that only a small proportion of injuries could be prevented by targeting injury preven tion at children identified by this method. ${ }^{2}$

The alternative to targeting injury preven tion to those at high risk, is to use a population approach. This is feasible in primary care in the् UK, where all children aged under 5 years see a general practitioner or practice nurse at leas 5 once a year. ${ }^{13} \mathrm{~A}$ programme of primary cares based child health surveillance currently exists? and has been found to reach children at hight risk of injury. ${ }^{14}$ This could be used to offe systematic age specific anticipatory injury prevention as described by The Injury Prevention Program (TIPP). ${ }^{15}$

This study, therefore, examines the relation ship between risk factors and injury outcomes 2 and assesses the feasibility of using risk factors to identify children at high risk. The findingso inform the decision regarding using a whole population or a targeted approach in a primary care intervention study.

\section{Methods}

A postal questionnaire was sent to all parents and older children (age 12-16 years) registered with the practice in $1993(\mathrm{n}=771)$. Nonresponders were reminded by telephone after 
two weeks and sent a further questionnaire if requested. Non-responders without a telephone were sent a second questionnaire. The questionnaire contained two sections; the first concerned age specific questions on safety practices and safety equipment possession and use, the results of which were not used for this study. The second section contained questions about risk factors for unintentional injury as identified from the published literature $^{1-10}$ and sociodemographic details. The reliability of the questionnaire was assessed by a test-retest procedure on a sample of 34 mothers from a child health clinic in a location with a similar socioeconomic profile to that of the study population. Consistency of responses was assessed by calculating $\kappa$ coefficients. The responses to four questions (age, sex, postcode, previous medically attended unintentional injury) were validated from the medical records of a systematic one in 10 sample of children of responders still registered with the practice one year after the survey. Where a child had left the practice the next child on the list was used. $\kappa$ Coefficients were calculated to assess the degree of agreement between the responses on the questionnaire and the data in the medical records.

One year later, all children still registered with the practice were followed up for the occurrence of injuries, by a manual and computer search of the primary care records and a computer search of the hospital records at the only local hospital with an accident and emergency department. Injury severity was calculated using the 1990 version of the abbreviated injury scale (AIS). ${ }^{16}$ Non-responders to the questionnaire who were still registered with the practice were followed up in the same way. The outcomes used for this study were primary care and accident and emergency attendances and hospital admissions for unintentional injury.

The data were analysed using $\chi^{2}$ tests for categorical data. As the number of injuries by each risk factor was skewed to the left, comparisons were made by transforming the data using $\sqrt{x+1}$ for the number of injuries and by undertaking unpaired $t$ tests. Multivariate analyses, using logistic regression, were conducted with the outcomes of any attendance at any health care facility for unintentional injury or not, primary health care team attendance or not, accident and emergency department attendance or not, or hospital admission or not. Multiple linear regression analysis was used to adjust for confounding factors for the number of injuries. All data were analysed using the SPSS-PC package. The estimated number of children needing an injury prevention intervention to prevent one injury was calculated using the numbers needed to treat method described by Sackett et $a l^{17}$ based on an estimated $10 \%$ reduction in injury frequency achievable by a primary care based intervention. ${ }^{18} 19$

\section{Results}

Altogether 587 questionnaires were returned, giving a response rate of $78 \%$. Twenty one of the questionnaires used for reliability testing were returned $(62 \%)$. Twelve questions had identical responses on both questionnaires and a $\kappa$ coefficient of 1.00 . The remaining two questions had $\kappa$ coefficients of 0.94 and 0.87 .

The age, sex of the child, and postcode recorded on the questionnaires were identical to that recorded in the notes for all $\mathbf{5 8}$ children. The $\kappa$ coefficient for medically attended injuries was 0.81 .

The age distribution of children for whom questionnaires were completed did not differ significantly from that of the non-responders $\left(\chi^{2}=6.1,4\right.$ degrees of freedom, $\left.\mathrm{p}=0.19\right)$, but significantly fewer parents of girls responded $\left(\chi^{2}=9.6,1\right.$ degree of freedom, $\left.\mathrm{p}=0.002\right)$. Over the one year follow up period, 47 children left the practice. Of the 540 children still registered, 96 children had a total of 133 injuries, accounting for 141 attendances at a health care facility. Seventy of these attendances were treated by the primary health care team, 67 at the accident and emergency department, and four children were admitted to hospital after injury. The injury rate was 246 injuries per 1000 children per year, that for non-responders was 357 per $1000\left(\chi^{2}=3.27,1\right.$ degree of freedom, $\mathrm{p}=0.07)$. The AIS scores of all injuries ranged from $1-3$, with $87 \%$ having a score of one. Not surprisingly, with such little variation in scores, there were no significant associations between injury severity and any of the risk factors.

Based on univariate analyses, only a history of a previous medically attended injury was significantly associated with attendance at any health care facility, attendance at the accident and emergency department, and at the primary health care team. Male sex was significantly associated with attendance at the accident and emergency department only. None of the other factors showed any significant association with any injury outcome.

The relative risk and $95 \%$ confidence interval (CI) for each injury outcome by each risk and sociodemographic factor are shown in table 1 . Logistic regression models were fitted for each outcome variable. Models were built using forward and backward stepwise selection and by entering all variables on one step. Each method produced identical models for each outcome. The final model for all injury attendances and for primary health care team attendances included only previous injury (odds ratio (OR) 2.33 , 95\% CI 1.37 to 4.05 and OR $2.58,95 \%$ CI 1.33 to 5.00 , respectively). The final model for accident and emergency attendances included male sex (OR 2.13, 95\% CI 1.06 to 4.20 ) and previous injury (OR $2.27,95 \%$ CI 1.15 to 4.40 ). These models were used to estimate the probability of each injury outcome based on the presence or absence of the significant factors. A history of previous medically attended injury increased the probability of a medically attended injury over the next year from 0.26 to 0.43 , and that of primary health care team attendance from 0.16 to 0.27 . Being male and having a history of previous medically attended injury increased 
Table 1 Relative risk of primary health care team attendance, accident and emergency department attendance at any health care facility for unintentional injury, by univariate analyses of risk and sociodemographic factors (95\% CI)

\begin{tabular}{|c|c|c|c|c|c|}
\hline $\begin{array}{l}\text { Risk or sociodemographic } \\
\text { factor }\end{array}$ & $\begin{array}{l}\text { No of children } \\
\text { with risk } \\
\text { factor }\end{array}$ & $\begin{array}{l}\text { Primary health care } \\
\text { team attendance }\end{array}$ & $\begin{array}{l}\text { Accident and } \\
\text { emergency department } \\
\text { attendance }\end{array}$ & All attendances & ב \\
\hline Male sex & 292 & $1.08(0.65$ to 1.79$)$ & $1.68(1.01$ to 2.80$)$ & $1.19(0.82$ to 1.74$)$ & (7) \\
\hline Age $<5$ years & 187 & $1.00(0.59$ to 1.70$)$ & $0.80(0.49$ to 1.29$)$ & $0.97(0.66$ to 1.41$)$ & \\
\hline$\geqslant 4$ children in family & 62 & $1.29(0.64$ to 2.62$)$ & $1.30(0.67$ to 2.53$)$ & $1.18(0.69$ to 2.00$)$ & \\
\hline Single parent family & 57 & 1.95 (0.98 to 3.87$)$ & $0.92(0.41$ to 2.04$)$ & $1.06(0.59$ to 1.88$)$ & \\
\hline Non-owner occupier & 62 & $1.27(0.63$ to 2.58$)$ & $0.44(0.14$ to 1.36$)$ & $0.92(0.50$ to 1.69$)$ & \\
\hline No access to car & 37 & $1.05(0.40$ to 2.77$)$ & $0.73(0.24$ to 2.23$)$ & $0.77(0.33$ to 1.80$)$ & \\
\hline Ethnic group non-white & 22 & & $0.40(0.06$ to 2.74$)$ & $0.25(0.04$ to 1.69$)$ & t \\
\hline Receipt of means tested benefit & 79 & $1.39(0.74$ to 2.59$)$ & $0.66(0.26$ to 1.49$)$ & 0.99 (0.57 to 1.67$)$ & \\
\hline $\begin{array}{l}\text { Maternal age } \leqslant 20 \text { years at } \\
\text { birth of first child }\end{array}$ & 35 & $0.79(0.26$ to 2.43$)$ & $0.70(0.23$ to 2.19$)$ & $0.80(0.34$ to 1.85$)$ & 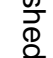 \\
\hline $\begin{array}{l}\text { Previous medically attended } \\
\text { injury }\end{array}$ & 239 & 1.79 (1.06 to 3.02$)$ & 1.64 (1.01 to 2.68$)$ & $1.52(1.04$ to 2.21$)$ & \\
\hline Overcrowding & 28 & 1.70 (0.73 to 3.98$)$ & 0.65 (0.17 to 2.55$)$ & $1.01(0.44$ to 2.32$)$ & \\
\hline Unemployment & 20 & 1.43 (0.48 to 4.25$)$ & $0.47(0.07$ to 3.21$)$ & 1.11 (0.44 to 2.77 ) & \\
\hline Townsend score $>0$ & 97 & $1.28(0.71$ to 2.31$)$ & $1.01(0.84$ to 1.90$)$ & $1.07(0.67$ to 1.71$)$ & \\
\hline
\end{tabular}

Table 2 Univariate analyses of the mean number of injuries by risk and sociodemographic factors

\begin{tabular}{|c|c|c|c|c|c|}
\hline $\begin{array}{l}\text { Risk or sociodemographic } \\
\text { factor }\end{array}$ & $\begin{array}{l}\text { No of } \\
\text { children * }\end{array}$ & $\begin{array}{l}\text { Mean }(S D) \\
\text { No of injuries }\end{array}$ & $t$ & $d f$ & p \\
\hline $\begin{array}{l}\text { Male } \\
\text { Female } \\
\text { Age (years) }\end{array}$ & $\begin{array}{l}292 \\
246\end{array}$ & $\begin{array}{l}1.06(0.28) \\
1.06(0.22)\end{array}$ & -0.38 & 534 & 0.70 \\
\hline $\begin{array}{l}<5 \\
\geqslant 5\end{array}$ & $\begin{array}{l}187 \\
353\end{array}$ & $\begin{array}{l}1.05(0.26) \\
1.07(0.24)\end{array}$ & 0.81 & 538 & 0.41 \\
\hline $\begin{array}{l}\text { No of children in family } \\
<4 \\
\geqslant 4\end{array}$ & $\begin{array}{l}474 \\
62\end{array}$ & $\begin{array}{l}1.06(0.24) \\
1.10(0.30)\end{array}$ & -0.96 & 72 & 0.34 \\
\hline $\begin{array}{l}\text { Ethnic group } \\
\text { White } \\
\text { Non-white }\end{array}$ & $\begin{array}{l}489 \\
22\end{array}$ & $\begin{array}{l}1.06(0.25) \\
1.02(0.09)\end{array}$ & 2.04 & 39 & 0.05 \\
\hline $\begin{array}{l}\text { No of parents } \\
\text { Single } \\
\text { Two }\end{array}$ & $\begin{array}{l}57 \\
465\end{array}$ & $\begin{array}{l}1.10(0.32) \\
1.06(0.24)\end{array}$ & 0.91 & 64 & 0.37 \\
\hline $\begin{array}{l}\text { Access to car } \\
\text { No } \\
\text { Yes }\end{array}$ & $\begin{array}{l}37 \\
490\end{array}$ & $\begin{array}{l}1.04(0.28) \\
1.07(0.25)\end{array}$ & 0.54 & 525 & 0.60 \\
\hline $\begin{array}{l}\text { Home ownership } \\
\text { Owner occupier } \\
\text { Non-owner occupier }\end{array}$ & $\begin{array}{l}466 \\
62\end{array}$ & $\begin{array}{l}1.06(0.25) \\
1.06(0.25)\end{array}$ & 0.03 & 526 & 0.98 \\
\hline $\begin{array}{l}\text { Receipt of benefits } \\
\text { Yes } \\
\text { No } \\
\text { Maternal age (years) }\end{array}$ & $\begin{array}{l}79 \\
445\end{array}$ & $\begin{array}{l}1.07(0.31) \\
1.06(0.24)\end{array}$ & 0.22 & 96 & 0.83 \\
\hline $\begin{array}{l}\leqslant 20 \\
>20\end{array}$ & $\begin{array}{l}35 \\
435\end{array}$ & $\begin{array}{l}1.05(0.35) \\
1.10(0.25)\end{array}$ & -2.60 & 468 & 0.01 \\
\hline $\begin{array}{l}\text { Employment } \\
\text { No } \\
\text { Yes }\end{array}$ & $\begin{array}{l}20 \\
520\end{array}$ & $\begin{array}{l}1.09(0.30) \\
1.07(0.25)\end{array}$ & 1.22 & 538 & 0.22 \\
\hline $\begin{array}{l}\text { Overcrowding } \\
\text { Yes } \\
\text { No }\end{array}$ & $\begin{array}{l}28 \\
511\end{array}$ & $\begin{array}{l}1.08(0.35) \\
1.06(0.24)\end{array}$ & 0.22 & 28 & 0.83 \\
\hline $\begin{array}{l}\text { Residency } \\
\text { Non-deprived area } \\
\text { Deprived area }\end{array}$ & $\begin{array}{l}394 \\
97\end{array}$ & $\begin{array}{l}1.07(0.24) \\
1.04(0.30)\end{array}$ & 1.02 & 127 & 0.31 \\
\hline $\begin{array}{l}\text { Previous injury } \\
\text { Yes } \\
\text { No }\end{array}$ & $\begin{array}{l}239 \\
289\end{array}$ & $\begin{array}{l}1.10(0.28) \\
1.04(0.22)\end{array}$ & 2.77 & 445 & 0.006 \\
\hline
\end{tabular}

${ }^{\star} \mathrm{n}=540$. Cases with missing data on a particular variable have been excluded $\mathrm{df}=$ degrees of freedom.

Table 3 The sensitivity, specificity, and positive predictive value of risk and sociodemographic variables for predicting future injury and the number of children in each risk factor group needing to be targeted for injury prevention to prevent one injury*

\begin{tabular}{|c|c|c|c|c|}
\hline $\begin{array}{l}\text { Risk or sociodemographic } \\
\text { factor }\end{array}$ & $\begin{array}{l}\text { Sensitivity } \\
(\%)\end{array}$ & $\begin{array}{l}\text { Specificity } \\
(\%)\end{array}$ & $\begin{array}{l}\text { Positive } \\
\text { predictive } \\
\text { value }\end{array}$ & $\begin{array}{l}\text { No of children to } \\
\text { target per injury } \\
\text { prevented }(95 \% \text { CI) }\end{array}$ \\
\hline $\begin{array}{l}\text { Male sex } \\
\text { Age }<5 \text { years } \\
\geqslant 4 \text { children in family } \\
\text { Single parent family } \\
\text { Non-owner occupier } \\
\text { No access to car } \\
\text { Receipt of benefits } \\
\text { Ethnicity } \\
\text { Maternal age } \leqslant 20 \text { years } \\
\text { Previous medically } \\
\text { attended injury }\end{array}$ & $\begin{array}{l}59.4 \\
35.4 \\
13.7 \\
11.6 \\
10.7 \\
5.3 \\
14.9 \\
1.1 \\
5.8 \\
57.4\end{array}$ & $\begin{array}{l}46.8 \\
65.5 \\
88.9 \\
89.2 \\
88.0 \\
92.6 \\
84.9 \\
95.0 \\
92.2 \\
57.4\end{array}$ & $\begin{array}{l}19.5 \\
18.2 \\
21.0 \\
19.2 \\
16.1 \\
13.5 \\
17.7 \\
4.5 \\
14.2 \\
22.6\end{array}$ & $\begin{array}{l}38(24 \text { to } 52) \\
38(27 \text { to } 49) \\
27(21 \text { to } 33) \\
25(19 \text { to } 31) \\
43(36 \text { to } 50) \\
33(28 \text { to } 38) \\
30(23 \text { to } 37) \\
25(17 \text { to } 33) \\
34(29 \text { to } 39) \\
29(20 \text { to } 38)\end{array}$ \\
\hline $\begin{array}{l}\text { Overcrowding } \\
\text { Unemployment } \\
\text { Townsend score >0 } \\
\text { Whole population }\end{array}$ & $\begin{array}{l}5.3 \\
4.2 \\
21.1\end{array}$ & $\begin{array}{l}94.8 \\
96.4 \\
80.5\end{array}$ & $\begin{array}{l}17.9 \\
20.0 \\
19.6\end{array}$ & $\begin{array}{l}54(49 \text { to } 59) \\
50(46 \text { to } 54) \\
34(26 \text { to } 42) \\
38(18 \text { to } 58)\end{array}$ \\
\hline
\end{tabular}

^ Estimated $10 \%$ reduction in injury frequency as result of injury prevention intervention. ${ }^{1819}$ the probability of accident and emergencys attendance over the next year from 0.28 to 0.52 음

Using the number of injuries as the outcomemeasure, previous medically attended injurs and young maternal age at birth of first chils were associated with a significantly highe $\mathrm{B}$ number of injuries (table 2). Multiple linea regression produced identical results as the univariate analyses. The predicted number of injuries in the subsequent year, based on the final regression equation for a child with mother aged over 20 at the birth of her firs child who has had at least one previous medically attended injury is 1.11 , whereas child with a mother aged 20 or under at the birth of their first child who has not had $\overrightarrow{\mathbb{D}}$ previous medically attended injury has predicted number of injuries in the subsequeng year of 0.99 .

The number of children and the number of injuries occurring to children in each risk facto group is shown in table 3, along with the sensitivity, specificity, and positive predictive value for each factor in predicting which children will suffer future injury. These results demonstrate that the sensitivity and positive predictive value is low for most factors; thus the number of children needed to be targete $\$$ for injury prevention does not differ signifi cantly from the number who would need to receive an intervention if a population ap proach was used.

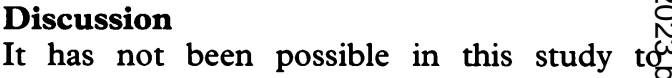
replicate the associations previously found between risk factors for childhood injury an many injury outcomes. It is important to? consider the possible explanations for this because the implications of this finding are that such risk factors should not be used fo targeting primary care based interventions $\frac{\mathbb{R}}{\mathrm{B}}$ Chance, bias, confounding, or a true lack of association are all potential explanations which need to be considered.

$A$ posteriori sample size calculations indicate that the study was sufficiently powerful ( $80 \% \frac{0}{5}$ power, $5 \%$ significance level) to detect $\vec{a}$ relative risk of a medically attended injury of less than 2 for male sex, four or more children 
in family, non-owner occupation, receipt of means tested benefits, and previous medically attended injury. As attendance at the primary health care team and at the accident and emergency department were less common outcomes, the study was only able to detect larger relative risks for these outcomes. Previous studies have found relative risks of this magnitude (that is 2 or less) for child age, maternal age, single parenthood, previous medically attended injury, sex, and socioeconomic disadvantage. ${ }^{12351220-24}$ Therefore, it seems unlikely that a type II error can explain the lack of association found between most risk factors and having at least one medically attended injury.

Previous work suggests that responders to postal questionnaires often differ from nonresponders in terms of demographic and socioeconomic factors such as age, sex, social class, ethnicity, ${ }^{25} 26$ and single parenthood. ${ }^{27} 28$ A response bias has been demonstrated in which girls and older children with a history of previous medically attended injury were underrepresented among the responders. Also, the unintentional injury rate over the follow up year was higher in children of non-responders. Previous studies in primary care and accident and emergency settings have found injury rates similar to that of children of responders found in this study, ${ }^{132930}$ so it is unlikely that response bias will have had a major effect on the results. Furthermore, assuming that all children of non-responders had a history of previous injury and experienced the injury rate for non-responders found in this study, the relative risk for a future injury in those with a history of previous injury would increase from 1.79 to 2.05 , which would not substantially alter the results.

Much of the work on risk factors for unintentional injury originated from the Child Health and Education Study, which commenced 25 years ago, based on a population comprising all children born in one week in England and Wales. It is possible that the variables used in this study have not been able to identify a group of children at high risk of injury because of changes in social structure over time or because of the relatively affluent population used in this study. ${ }^{31}$ Some variables are directly comparable betweeen the two studies: the Child Health Education Study had less than $5 \%$ of their study population with four or more children in each family, ${ }^{7}$ compared with $11.8 \%$ in this study; fewer than $5 \%$ of the children came from single parent families ${ }^{9}$ compared with $9.7 \%$ in this study, and $8.6 \%$ of mothers whose first child was born before the age of 20 years ${ }^{8}$ compared with $6.5 \%$ in this study. Over the last 25 years single parenthood has become more prevalent and single parents are an increasingly heterogeneous socioeconomic group. ${ }^{32}$ Maternal age at birth of first child has risen over the same period. ${ }^{33}$ The children of such single parents or young mothers today may therefore have differing risks of injury than they did at the time of the Child Health and Education Study.

The use of a relatively affluent population may influence the utility of the risk factors for identifying children at high risk of injury. The experience of poverty or disadvantage cannot be separated from social context, hence variables used to describe socioeconomic status may reflect different life experiences in a relatively affluent area than in a deprived area. For example, non-owner occupation in an affluent area may be a qualitatively different experience than non-owner occupation in a deprived area where other facilities such as safe play or leisure areas are less likely to be available. The risk factors may therefore be more discriminating in terms of injury risk in a less advantaged population.

A further difficulty with some of the risk factors used in this study is that their presence may be less important than their duration. For example, long term unemployment is likely to reflect different socioeconomic-economic circumstances than short term unemployment, such as increasing financial difficulty, increasing frequency of stressful life events, decreasing quality of the home environment, increasing social isolation and reduced self esteem, ${ }^{24}$ all of which may be important in preventing injury. This study did not measure duration of indicators of socioeconomic disadvantage, but it may be useful for future work in this area to do so.

Confounding factors such as proximity to hospital, maternal inexperience in dealing with injury and non-accidental injury are unlikely to explain the observed results. The practice area is geographically small and located close to the accident and emergency department. Children with older mothers were found to suffer a greater number of injuries than children with younger (and possibly more inexperienced) mothers. This is contrary to what would be expected if maternal inexperience was a confounding variable. At present none of the children registered with the practice are on the child protection register, so non-accidental injury is unlikely to be a plausible explanation.

It is possible that factors relating to health service utilisation are confounding the relationship between risk factors and injury occurrence because the majority of injuries in this study were minor. This suggestion is supported by the findings of the Walsh and Jarvis who examined cases of moderate (injury severity score (ISS) $\geqslant 4$ ) or severe injury (ISS $\geqslant 9$ ) and death and found a significant association between socioeconomic status (measured by Townsend index) and injury. ${ }^{35}$ The gradient was steepest for fatal injuries and least steep for more minor injuries. The preponderance of minor injuries does mean that the results of this study cannot be generalised to more severe injuries, and that where strong associations exist between severe or fatal injuries and risk factors, targeting injury prevention may be worthwhile. Even then, it will only be an effective strategy if the majority of injuries occur in the high risk group.

Insufficient power, bias, and confounding therefore do not provide adequate explanation for the lack of an association between the risk factors and the injury outcomes. Three recent 
studies of attendances at accident and emergency departments for unintentional injury have also failed to find associations between area based measures of deprivation and attendance $^{123637}$ supporting the hypothesis that for more minor injuries some of the previously demonstrated associations may no longer exist. A case-control study undertaken in Glasgow in 1995 found only previous injury and male sex to be significantly associated with such attendances after unintentional injury, with similar ORs to those found in this study, but no association between an area based deprivation score or ethnicity and attendance for injury. ${ }^{12}$ Lyons and colleagues, in a larger accident and emergency department based study using the Townsend index of deprivation, suggested that their failure to find an association may be explained by the ecological fallacy where the association at an aggregate level does not necessarily represent the association found at the individual level. ${ }^{36}$ This may occur if the Townsend index does not describe homogenous areas, in which case data at the level of the individual will be more useful than aggregate data. The lack of any associations between the individual components of the index and any of the outcomes does not support this hypothesis, but further work is needed with a larger sample size to examine the relationship between individual measures of deprivation and injury outcome before stronger conclusions can be drawn about the ecological fallacy.

\section{Implications for prevention}

The failure to find significant associations between risk factors and a range of injury outcome measures suggests that, at present, primary care injury prevention programmes should not be targeted using these risk factors. Such a strategy should await further work to confirm or refute this finding in a larger population with a wider cross section of socioeconomic status. The low sensitivity and positive predictive value for each of the factors (except male sex and previous injury) means that for most risk factors the factor will miss most of the children who will have an injury in the subsequent year, because they are not in the high risk group. At the same time it will identify a large proportion of children as being at high risk who will not have an injury. The high specificity for most factors means they will correctly identify most of the children who will not have an injury. The number of children needed to treat to prevent one injury does not differ significantly using the targeted or population approach, but only the population approach has the potential to prevent all injuries.

This study, therefore, supports previous suggestions that targeting injury prevention at groups of high risk children is not efficient in terms of the number of children that would have to be targeted and the potential number of injuries prevented. Instead, as children have repeated contacts with members of the primary health care team, especially in the first five years of life and as injury prevention pro- grammes, such as TIPP, do exist which could be incorporated into these contacts it is suggested that primary care injury prevention programmes should use a population ap proach.

In terms of prevention in settings other than primary care and in populations suffering more severe injuries, more work is needed assessing the efficiency of targeted versus population strategies.

1 Bijur PE, Golding J, Haslam M. Persistence of occurrence of injury: can injuries of preschool children predicis injuries of school-aged children? Pediatrics 1988; 82:$707-11$.

2 Eminson CJ, Jones H, Goldacre M. Repetition of accidentsin young children. $\mathcal{F}$ Epidemiol Community Health 1986. 40: $170-3$.

3 Sellar C, Ferguson JA, Goldacre MJ. Occurrence ant repetition of hospital admissions for accidents in pre school children. $B M \mathscr{F}$ 1991; 302: 16-9.

4 Boyce WT, Sobolewski S. Recurrent injuries in school- $\omega$ children. Am $\mathcal{F}$ Dis Child 1989; 143: 338-42.

5 Kendrick D. Accidental injury attendances as predictors of future admission. F Public Health Med 1993; 15: 171-4.0

6 Bijur P, Golding J, Haslum M, Kurzon M. BehaviouraP predictors of injury in preschool children. Am $\mathcal{F}$ Dis Child 1988; 142: 1307-12.

7 Bijur P, Golding J, Kurzon M. Childhood accidents, family size and birth order. Soc Sci Med 1988; 26: 839-43.

8 Taylor B, Wadsworth J, Butler NR. Teenage mothering, admission to hospital and accidents during the first years. Arch Dis Child 1983; 58: 6-11.

9 Wadsworth J, Burnell I, Taylor B, Butler N. Family type and accidents in preschool children. $\mathcal{F}$ Epidemiol Commur nity Health 1983; 37: 100-4.

10 Stewart-Brown S, Peters TJ, Golding J, Bijur P. Casedefinition in childhood accident studies: a vital factor in determining results. Int 7 Epidemiol 1986; 15: $352-9$.

11 Department of Health. The health of the nation. Key areas handbook: accidents. London: Department of Health, handb.

12 Ohn TT, Harper Gilmour W, Stone D. Pattern and risks oह̋ accidental injuries in children presenting to a paediatricD accident and emergency department. Maternal and Child Health 1995; December 404-7.

13 Office of Population Censuses and Surveys. Morbidity statistics from general practice. Fourth national study $1991-$ 1992. Series MBS No 3. London: HMSO, 1995.

14 Kendrick D, West J, Wright S, Presbury M. Does routine child health surveillance reach children most at risk of accidental injury? F Public Health Med 1995; 17: 39-45.

15 American Academy of Pediatrics. The injury prevention program. Early childhood safety counselling schedule. Illinois: program. Early childhood safety counselling

16 Association for the Advancement of Automotive Medicine The abbreviated injury scale: 1990 revision. Illinois: Asso-ciation for the Advancement of Automotive Medicine, 1990.

17 Sackett DL, Haynes RB, Guyatt GH, Tugwell P. Clinica $\bar{B}$ epidemiology: a basic science for clinical medicine. Boston Little Brown, 1991.

18 Kravitz $\mathrm{H}$, Grove $M$. Prevention of falls in infancy by counseling mothers. Illinois Medical fournal 1973; 144. $570-3$.

19 Bass J, Mehta K, Ostrovsky M. Childhood injury prevention in a suburban Massachusetts popoulation. Public Health Rep 1991; 106: 437-42.

20 Miller FJW, Court SDM, Knox EG, Brandon S. The schoo years in Newcastle-upon-Tyne. London: Oxford University Press, 1974.

21 Department of Trade and Industry. Home and leisure acciden research. 1992 data. Sixteenth annual report of the home accident surveillance system. London: Department of Trade and Industry, 1994.

22 Roberts I. Sole parenthood and the risk of child pedestrian ${ }^{\omega} \omega$

23 Manheimer DI, Dewey J, Mellinger GD, Corsa L. 50,000 child years of accidental injuries. Public Health Rep 1966 81: $519-33$.

24 Constantinides P. Safe at home? Children's accidents and inequality. Radical Community Medicine 1988; Spring: $31-4$

25 Cartwright A. Health surveys in practice and in potential: critical review of the scope and methods. London: Kings critical review

26 Streiner DL, Norman GR. Health measurement scales: $\vec{D}$ practical guide to their development and use. New York Oxford University Press, 1989.

27 Reeves J, Kendrick D, Denman S, Roberts H. Lone mothers: their health and lifestyle. Health Education fournal 1994; 53: 291-9.

28 South East Thames Regional Health Authority. Health ques south east regional report. London: South East Thames Regional Health Authority, 1993.

29 Steele K, Grandidier H, Mills K, Gilmore B, McGlade K, Reilly $P$. Accidents in the community: a role for the primary health care team? Health Education foumal 1994; 53: $73-80$. 
30 Agass M, Mant D, Fuller A, Coulter A, Jones L. Childhood accidents: a practice survey using general practitioner's records and parental reports. Br f Gen Pract 1990; 40: $202-5$.

31 Office of Population Censuses and Surveys. 1991 Census. Report for England. Regional health authorities parts 1 and 2. London: HMSO, 1993.

32 Marsh A, McKay S. Poor smokers. London: Policy Studies Institute, 1994.

33 Werner B. Fertility statistics from birth registrations in England and Wales, 1837-1987. Population Trends 1987 40: $4-10$.

34 Bartley $M$. Unemployment and health: understanding the relationship. I Epidemiol Community Health 1994; 48: $333-7$.

35 Walsh SS, Jarvis SN. Measuring the frequency of 'severe' accidental injury in childhood. $f$ Epidemiol Community Health 1992; 46: 26-32.

36 Lyons RA, Vui Lo S, Heaven M, Littlepage BNC. Injury surveillance in children-usefulness of a centralised database of accident and emergency attendances. Injury Prevention 1995; 1: 173-6.

37 McKee CM, Gleadhill DNS, Watson JD. Accident and emergency attendance rates: variation among patients from different general practices. Br F Gen Pract 1990; 40: $150-3$.

\section{THE BOOK OF ACCIDENTS;}

DESIGXED

FOR YOUNG CHILDREN.

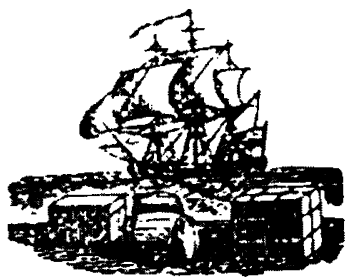

NEW-HA VEX:

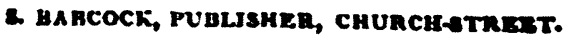

CHARI.XSTOX-8. BA ACOCE \& co.

shiecti Prew-1asa

\section{Book of Accidents}

This issue includes the first in a series of illustrations from The Book of Accidents; Designed for Young Children published in New Haven in 1830. Neither the writer nor illustrator is known. I discovered these pictures when Dr T E Cone (now of Massachusetts) arranged for their publication in Pediatrics in 1981. I am grateful to Dr Cone and to Pediatrics for allowing us to reproduce them. Apart from the delightful drawings, I wanted to share them with our readers because both the somewhat unfortunate title and the admonitory text accompanying most of the illustrations, so clearly reveal what was believed about injuries and their prevention a century ago. As you will discover, the onus is placed squarely and excusively on the child or parents, and it is clearly 'accidents' that these, largely middle and upper class families, are depicted as trying to prevent, mostly by giving advice to their children. I wonder how much most of society's attitudes have changed since then. 